\title{
The cost-effectiveness of water augmentation and management: Assessing the Unit Reference Value
}

\author{
R Bester, J N Blignaut, P H van Niekerk
}

As societies develop, the problem of securing and mobilising adequate water resources to support and sustain economic and social activities increases in complexity. As a costeffectiveness measure the use of the Unit Reference Value (URV) has become standard practice in South African water resource management and development. It is informative and easy to understand. These two attributes inspire confidence and an ever-greater uptake of its use in evaluating suggested courses of action to be taken by society in ensuring their future. Deviations in how an URV is calculated emerge due to both the diversification of its user base and the dynamic nature of the contexts in which it is applied. Such developments add to the pluralistic framings within which research and decision-makers operate. We provide three sub-types of URV application, and caution against comparing URVs across categories. To mitigate possible confusion, we propose the development of standards/rules for the interpretation of URVs.

\section{INTRODUCTION}

The multifarious use, and even occasional abuse, of research methods and/or indicators are common features within the natural development of science and scientific progress. These multifarious uses often persist due to a resistance to integrative and collaborative learning approaches that emanate from the structure of the various formal and informal institutions involved in knowledgegenerating systems (Angelstam et al 2013). The gradual entrenchment of indicator adaptations has been cited as the cause for the increase in statistical errors in medical research (Glantz 1980), the development of expensive and ineffective educational practices (Alferink \& Farmer-Dougan 2010), private sector underinvestment (Drury \& Tayles 1997), and the increase in the incidence of physical injury caused to patients by medical practitioners (Brisson \& Brisson 2010). To tunnel through this pervasive resistance requires occasional reflection or, to borrow jargon from systems thinking, feedback to recalibrate. The question is, how do we conduct such mental feedback?

One proposed way is a systematic look at the Values (or norms), system Rules (or policies), and prevailing Knowledge at various stages (i.e. over time) and how that shaped the application, and thus change in and the use of any particular research methods and/ or indicators. This model, herein called the
VRK-framework, is based on the work of Goddard et al (2016), and has been developed for the analysis of contested, complex and cross-scale "problems". It is a very useful framework in the interpretation of the causes of the multifarious use of research methods and indicators, as emerging from the interaction between a universal value for the use of a particular method, and the evidence and practice-based knowledge inequalities between user groups or individuals.

Here we apply the VRK-framework to develop a deeper understanding of why, and how, South Africa's Unit Reference Value (URV) has been used in the recent past, and more specifically, how and why it has undergone various indicator adaptations. The URV is a cost-effectiveness measure developed for use in the pre-planning stages of water resource management and development projects. It assists decision-makers in allocating scarce resources in the most effective way by comparing, in a consistent manner, various water development schemes. Over time, however, the URV has been applied in various settings by an increasingly diversified user base. This resulted in a cumulative series of adaptations to the URV from a diverse knowledge base following the continuous application of it within varied new organisational and environmental contexts. While it could be argued that it would appear that the multifarious use of the URV has
JOURNAL OF THE SOUTH AFRICAN INSTITUTION OF CIVIL ENGINEERING ISSN 1021-2019

Vol 62 № 2, June 2020, Pages 39-44, Paper 0840

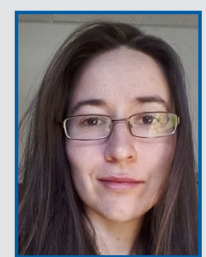

ROZANNE BESTER is a system dynamics modeller and researcher affliated with the Institute of Water Research (Rhodes University). She obtained a Master's degree in Economics at the University of Pretoria in 2016 and has since worked in restoration and development projects.

Contact details

Postnet Suite 47

Private Bag X16

Highveld Park 0169

South Africa

T: +27826122471

E:bester.roz@gmail.com

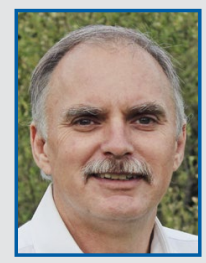

JAMES BLIGNAUT is a natural and environmental resource economist attached to both the School of Public Leadership, Stellenbosch, and the South African Environmental Observation Network (SAEON). He focuses on the economics of the restoration of degraded landscapes under the motto: The economics of

restoration and the restoration of economicc. He is especially focused on the advancement of regenerative agriculture and, within that context, proper resource use and allocation inclusive of the economic benefits of restoration.

Contact details SAEON Pretoria

and

School of Public Leadership

Stellenbosch University

Stellenbosch

South Africa

P: PO Box 144, Derdepark, 0035, South Africa

T: +27847204127

E: jnblignaut@gmail.com

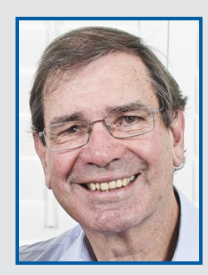

DR PETER VAN NIEKERK (Pr Eng, FSAICE) has more than 40 years of experience in the water resource planning and engineering field. From 1987 to 2009 he was responsible for all water resources planning in the Department of Water Affairs, South Africa. His extensive background includes international water resource sharing and management, and advanced academic studies in water resource economic analysis. He continues to provide specialist input with respect to the planning of hydrological, water supply and water resources projects.

Contact details

Water Resource Appraisal Services

POBox 47

Onrus River 7201

South Africa

T: +27283161968

E: waterappraisal@gmail.com

Keywords: Unit Reference Value (URV), Water Supply Management (WSM), Integrated Water Resources Management (IWRM), Values-RulesKnowledge (VRK) framework, decision-making 
supported useful policy interventions and necessary shifts in the narrative around the management of water resources, there is a risk that it might well be correlated with increased ineffectiveness in water management. This is due to the fact that the adaptations of the URV have remained largely unchallenged. This paper is an attempt to rectify this situation by conducting a critical review, based on the VRK-framework, of the use of the URV indicator in South Africa.

We commence with a discussion on the natural progression of the context within which the URV was developed, and which has also given rise to its multifarious use based on the VRK-framework. Thereafter we take a critical look at the various ways the URV has been calculated, and the implications thereof. This is followed by recommendations with respect to the future development thereof.

\section{CONTEXTUAL PROGRESSION AND THE GROWTH IN URV THINKING}

\section{Introduction}

The URV was developed in the 1980s by the then Department of Water Affairs. It was developed as a cost-effectiveness measure that computes the unitary cost of supplying a cubic metre of water at the required assurance of supply, over the portion of the water management or augmentation project's lifespan during which it produces economic benefits for society. In its most basic form the URV is calculated as the discounted present value of the total (capital and operational) lifecycle cost of a water augmentation or management scheme divided by the discounted incremental water availability assured by the expansion of the system and bounded by the projected demand curve until full capacity is reached (Van Niekerk \& Du Plessis 2013a). Discounting a natural resource stock such as water is a contested issue (Costanza et al 1989). However, the URV has adopted this approach in order to be able to compare, in a consistent manner, the URV ratios of different water development schemes, operating with different time horizons, which have different starting dates, thus avoiding an artificial lowering of the cost of water development by various schemes.

The URV, because of its simplicity in calculation and the ensuing intuitive understanding of the message it is carrying, has become a very powerful indicator with respect to water resource management and development. Over time it has become not

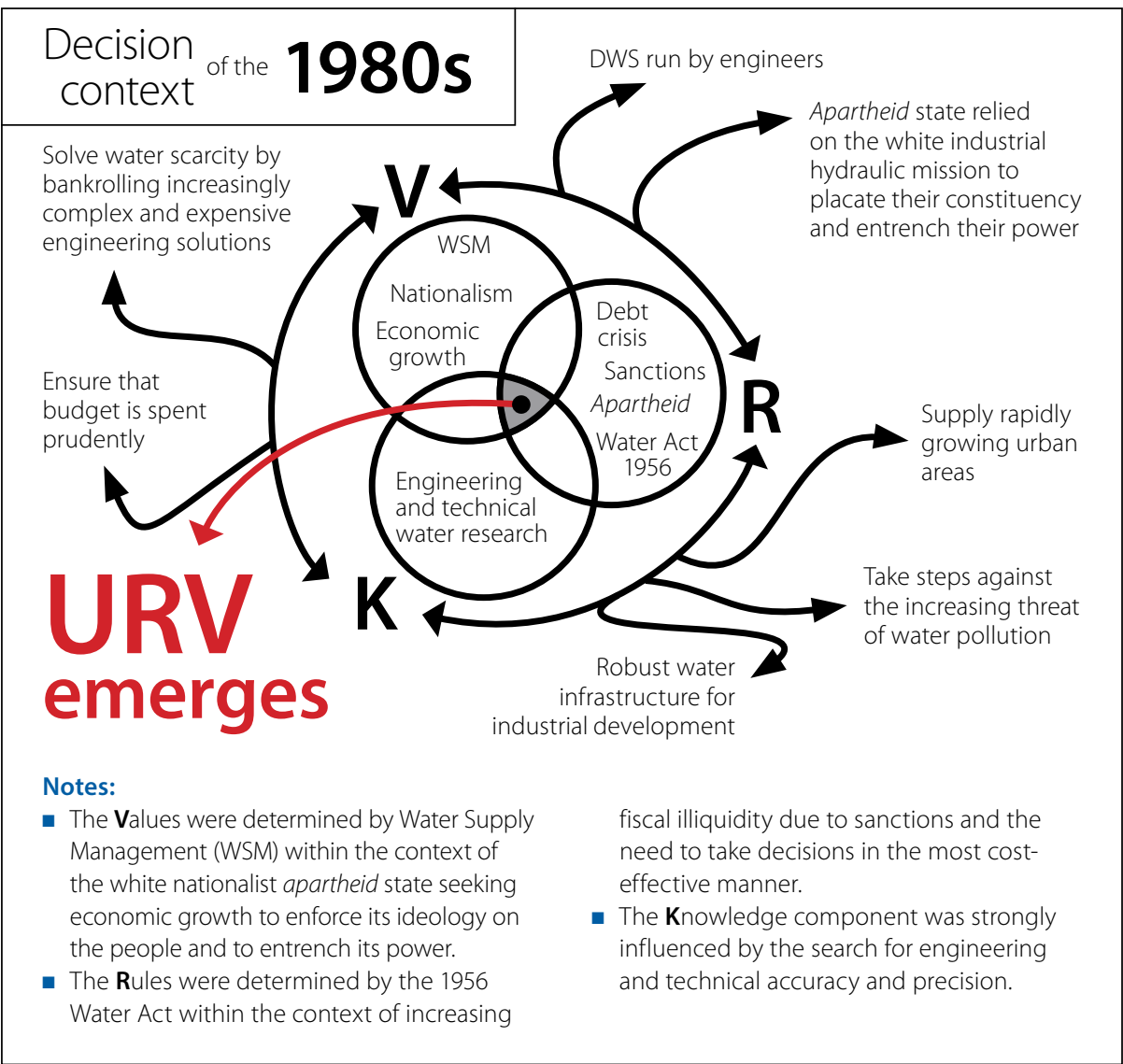

Figure 1 The decision context of the 1980s

only standard practice to calculate the URV for all water-related projects, but also mandatory within the context of any fiscal and budgetary process to motivate for financial or other resources. This natural progression with respect to the use and popularity of the URV coincided with a radical change within the political-social-economic and ecological context within which it has operated. We analyse this change at the hand of the aforementioned VRK-framework.

\section{Cross-temporal analysis of the context of water resource management}

Goddard et al (2016) proposed a values, rules and knowledge (VRK) framework with which to understand how a societal system of decision processes affects the manner in which a particular problem is addressed. We apply this framework to the South African decision-making context for water resource management, comparing a model of its state in the 1980s when the URV was developed (Figure 1) to a model of its current state (Figure 2).

In the 1980s water resource management was governed by Water Act No 54 of 1956. This Act required government to consolidate existing water legislation, and thus restructured the Department of Irrigation to form the Department of Water Affairs (DWA). The DWA had to ensure that there was sufficient water supply to support South Africa's growing social, economic and industrial development initiatives (Tempelhoff 2017). In addition to this drive towards the heavy capitalisation of the country, it took place within the context of a very unstable internal and external political economy. Thus, there was a need to manage water resources more effectively and to secure internal water security through water supply management (WSM) (Lowenberg 1997). This led to a very dominant supply-side policy focus and water research. This produced engineering and technically based solutions (Siebrits et al 2014). With the DWA chiefly the technocratic territory of engineers, plans for the expansion of water supply to cities and areas of industrial development were focused on increasingly complex and costly transfer schemes (Turton \& Meissner 2002). The URV was developed to assist in selecting the most cost-effective option first. This context is vastly different from that prevailing since the 1994 democratic elections and the rapid development of a natural resource management agenda - elements that have shaped the world of the current decade.

The prevailing context in the current decade is illustrated in Figure 2. Supply-side interventions were becoming costlier to implement just as the government, having been limited in their access to credit in 


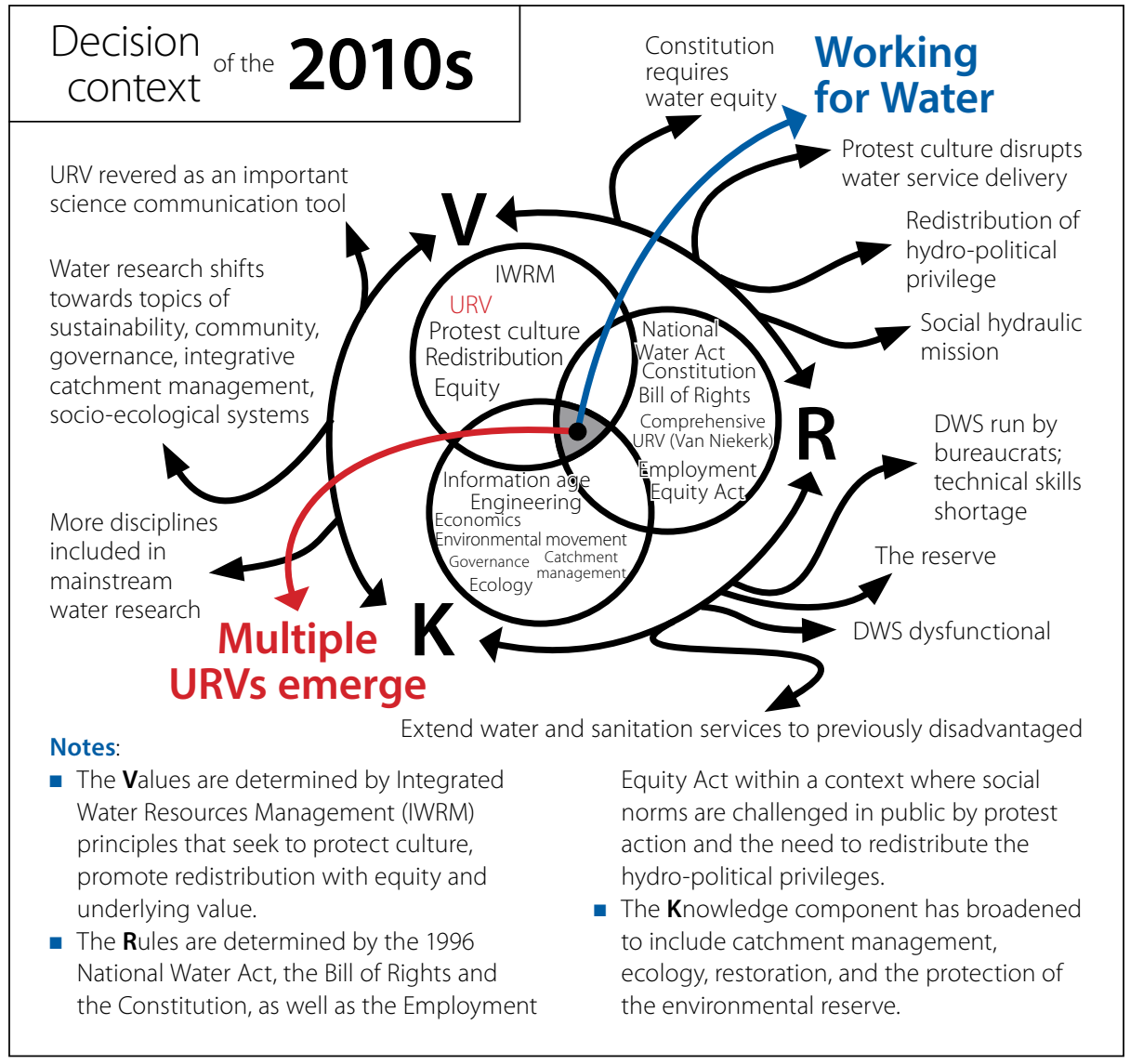

Figure 2 The decision context of the 2010s

response to their policies, was growing more reliant on the expansion of the water supply to support the needed growth of economic activity. In such an environment, the application of cost-effectiveness analysis to eliminate the costlier supply interventions early in the planning process was developed.

In post-apartheid South Africa, the policy of government is not one of expanding the water supply to support economic development, but rather of extending water services to the areas that were beyond the jurisdiction of the DWA under apartheid (Schreiner 2013). Integrative Water Resource Management (IWRM) had replaced WSM as the dominant paradigm, but the successful implementation of its policies and interventions has been questioned, and even failed (Ashton 2000; Denby et al 2016). The most widely held belief for its failure is that the persistent levels of poverty and high-income inequalities, which were carried over from the 1980s, limit the successful implementation of IWRM (Movik et al 2016). Water research is increasingly dominated by ecologists and economists as focus has shifted away from engineering and technical solutions towards concepts such as sustainability, governance, adaptation and management (Siebrits et al 2014). The URV is thus adapted and used as a science communication tool (Blignaut et al 2010; Mander et al 2017). A decision to fund the Working for Water (WfW) programme, which was made in 1995, had a positive impact on both the livelihoods of local communities and the availability of water, and has additionally promoted advances in biological control, raised conservation awareness, enacted legislation and promoted research (Binns et al 2001; Van Wilgen \& Wannenburgh 2016). The expansion of water delivery services is frustrated by a growing protest culture (Tapela 2012) and the Department of Water and Sanitation (DWS) is evaluated as being in a state of dysfunction, lacking technical personnel, institutional capacity and funding to perform maintenance on water infrastructure (Ruiters \& Matji 2015).

\section{Comparing two epochs}

The difference in social-political-ecological and institutional context between the 1980s and the current decade can hardly be greater. The 1980s were characterised by technocratic, success-seeking precision with a well-functioning and engineer-driven government department focused on water supply management to uphold a specific ideology of exclusivity and privilege. The current decade, however, is characterised by an inclusive, pluralistic and eco-anthropological ideology focused on integrated water resource management within the context of a hollow, and often failed, state (Morokong et al 2017).
It is in this latter context that multiple URVs emerged to assist and inform decision-makers.

\section{ADVANCES WITH RESPECT TO CALCULATING THE URV}

\section{Introduction}

The URV is, essentially, a knowledgegenerating tool. However, due to the contextual changes as described above, it became widely distributed for use across a broad number of organisational, sectoral and disciplinary boundaries. This made new applications possible that were not considered at first, or even deemed possible. Originally, in the 1980s, calculating a URV required one to take into consideration discounted lifecycle costs, projected water demand, the yield of the existing system including water transfers, and the incremental yield provided by the project being evaluated. The boundary of the problem is extended by the comprehensive URV to include an analysis of how each system's water demand and supply vectors vary over time and with respect to each other in the case of evaluating transfer schemes between two systems. In recent years, due to the multifarious use of the URV, the definition boundary has changed to exclude some core components of the original URV calculation, while expanding to include new components. A process, referred to above as indicator adaptation, occurred.

\section{The URV's many faces}

All the applications of the URV use the same definition with respect to costs, namely the numerator (i.e. the total capital or establishment costs plus the ongoing management and operation cost over time, discounted over the anticipated lifespan of the project). There are, however, at least three different interpretations with respect to the calculation of the denominator. We elaborate on these three below, labelling them URV1, URV2 and URV3 (as illustrated in Figure 3).

1. URV1 (the original version, see Figure 3: Panel A): The denominator is the additional water yield of a water development scheme bounded by a water requirement curve (Van Wilgen et al 1997; Larson et al 2001; Hosking \& Du Preez 2002; Van Niekerk \& Du Plessis 2013a, 2013b; DWS 2014; Blersch \& Du Plessis 2017).

2. URV2 (URV1, but adapted for water demand management, see Figure 3: Panel B): The denominator is the additional structural water yield surplus, or 


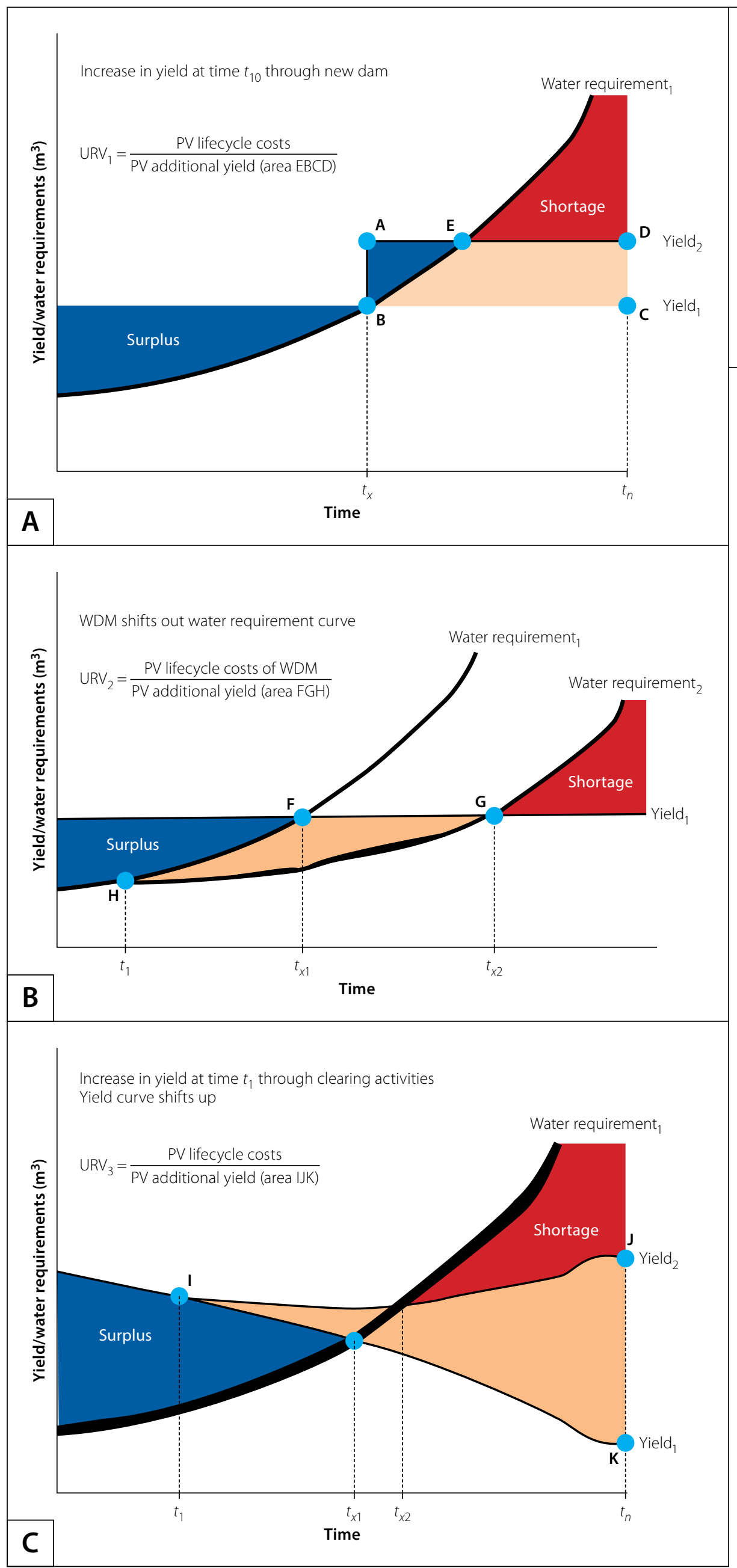

Figure 3 URV subtypes
Notes:

- Panel A: URV1 describes the case where the additional yield provided by a water project is calculated as the hatched area, bounded by the water requirement curve, which is effectively a reduction of future shortage.

- Panel B: URV2, which applies to water demand interventions; the quantity in the denominator (additional yield provided by the intervention) is taken as an increase in water surplus generated in the system.

- Panel C: URV3, the area taken as the additional yield is not bounded by the water requirement curve and includes both an increase in yield surplus and a decrease in shortage.

simply the "water saved" in response to demand-side management interventions (Joubert et al 2003; De Lange 2006; Hoffman \& Du Plessis 2008; Mckenzie \& Wegelin 2009; DWA 2011).

3. URV3 (URV1, but adapted to accommodate environmental management such as rehabilitation and the clearing of invasive alien plants, see Figure 3: Panel C): The denominator is the ability to increase either water yield or base flow in a system, irrespective of direct human consumption of that additional water for water services (Marais \& Wannenburgh 2008; Blignaut et al 2010; Preston 2015; Vundla et al 2016; Mander et al 2017; Morokong et al 2017; Nkambule et al 2017). It is used particularly where, due to uncertainty regarding the extent to which increased base flows will enhance the capacity of water infrastructure to meet societal demands, or indeed in the absence of such infrastructure for a river system all together, it has become the practice to forgo the consideration of a water requirement.

In literature, all three these methods, irrespective of the way in which the denominator is being defined and calculated, are called URV. This has the potential to lead to misguided outcomes and erroneous, and even inefficient, water resource management advice. The impacts of these three different ways of calculating the URV will be discussed at the hand of Figure 3, within the context of hypothetical examples.

\section{Example URV1:}

- Context: In Figure 3: Panel A, water demand increases over time and the water requirement of the system exceeds the water yield it can provide at time $t_{\mathrm{x}}$. A water project that becomes operational at time $t_{\mathrm{x}}$, and provides additional water yield (shifts out yield curve 1) of size A-B for 
the rest of the economic life of the system until time $t_{\mathrm{n}}$.

- Denominator: The URV used to evaluate the water project is concerned with the cost-effectiveness of the water project in enabling the system to meet its water requirements, and it discounts the hatched area (the area demarcated by EBCD) that is bounded by the system's projected water requirement curve.

\section{Example URV2:}

- Context: In Figure 3: Panel B, the water requirement of the system exceeds the water yield it can provide at time $t_{\mathrm{x} 1}$. Some water demand management measurements are implemented at time $t_{1}$, lowering the projected water requirement curve (shifting it down) and ensuring the system can meet its increasing demand for water until time $t_{\mathrm{x} 2}$. The system gains water surpluses (unused capacity) and delays the onset of future shortages.

- Denominator: The URV used to evaluate the water project discounts the hatched area (the area demarcated by FGH).

\section{Example URV3:}

- Context: In Figure 3: Panel C, the water requirement of the system exceeds the water yield it can provide at time $t_{\mathrm{x} 1}$, due to the spread of invasive alien plants (IAPs) which reduce runoff. In anticipation of future shortfall in the system's capacity to provide sufficient water, clearing of IAPs commences at time $t_{1}$ and continues for the economic life of the system until $t_{\mathrm{n}}$. Like other supply-side interventions, the yield curve is shifted upwards improving the system's ability to meet its increasing demand for water (by $t_{\mathrm{x} 2}-t_{\mathrm{x} 1}$ years).

- Denominator: In this case, the URV used to evaluate the water project discounts the hatched area (the area demarcated by KIJ). Here the total additional yield provided by the intervention is taken as measure of effectiveness, irrespective of whether or not this additional yield will be used in the system. This is in contrast to the example given in Panel A in which only the additional water bounded by the water requirement curve is used to evaluate the cost-effectiveness of the intervention.

\section{DISCUSSION}

The process of calculating a URV is a platform which supports the development of synergies to create new knowledge on a project by project basis (Siedlok \& Hibbert
2014). Above the line sits Economics/Finance, below the line sits Hydrology, Engineering and Ecology - and the URV analysis requires the inclusion of components from each. The emergence of a multifarious use of the URV, as seen in the previous section, can be explained by applying Argote and Miron-Spektor's framework (Argote \& MironSpektor 2011) for organisational learning. In each instance the URV tool was shaped through use to accomplish the objectives of the new user for the purpose of the adopting organisation. For example, the URV was adapted for use in evaluating IAPs and motivating for their removal. The diffusion of the URV tool across multiple organisations predisposed users to have and acquire divergent evidence and practise base knowledge endowment. This made the emergence of several distinct URV deviations a sure thing, as the concepts of cost-effectiveness or accompanying graphing techniques were lost during the translation of the tool between organisations, or were discarded over time.

By viewing the URV through the VRK and organisational learning frameworks, we conclude that, since its emergence in the 1980s, the use of the URV has succeeded to influence value systems and operating protocols at a societal level. Politicians and researchers are aware of, and wish to entrench, its usefulness as a science-management communication tool, hence the repeated use of the URV. The URV is also a point in analysis around which synergies occur, encouraging those who engage with it to be exposed to a more holistic view of a particular subsystem. Owing to changes in the decision context of South African water management, an influx of researchers from a broadening set of academic disciplines expanded the experiential and practical knowledge stock embedded within the original definition and use of the URV. Unfortunately, it is also potentially misleading, as it is, essentially, not the same indicator given the different definitions used for the denominator.

Given the externality benefits produced by the URV, any aim to address the multifarious use of it must not inhibit any freedom in the ease with which it can facilitate communication between scientists and managers, or allow for innovation that comes from moving the problem boundary. Context is thus important and valuable, and additional rules imposed on its calculation must serve the pluralistic operational context. The co-habitation of the three URV formulae used, however, provides sufficient space for such a pluralistic environment.

\section{CONCLUSION}

The Unit Reference Value (URV) has been used in South Africa for more than 30 years, initially by water engineers, and later hydrologists, economists and ecologists alike within a drastically changed social-politicalecological and institutional context. As a costeffectiveness measure it is highly informative and intuitively easy to understand - both aspects that generate further support for its use. Over time however, the multifarious use thereof has led to various ways in which researchers calculated its denominator, to the extent that, effectively, the results across the different types of URV measures cannot be compared without some discussion and distinction. This does not imply that the new developments have been wrong. Rather, they have added to the pluralistic context within which research and decision-makers operate, and is a good reflection of the current and emerging debates.

To mitigate against possible confusion and to avoid the misinterpretation of the results, we recommend the following:

- The introduction of naming conventions for different URV subtypes, namely URV1, URV2 and URV3, as per the above categories thereof. This would force URV users to make type-for-type comparisons and reach conclusions that can be supported from the theory, and which would make type-for-type comparisons possible. This will interact with the values and knowledge components to self-regulate further expansion.

- The redefining of the appropriate measure for all the URVs as "the unit cost to reduce future water shortage, or to enhance water security, using measure 1,2 , or 3 " - that will be applicable in most interventions.

- That URV users provide, not only a formula or description of the URV calculation according to the type they are reporting on, but also a diagram illustrating what the effectiveness measure is that they are calculating. This would imply that users will engage with many of the principles underlying the URV and potentially be a point of learning between individuals that could reduce knowledge inequalities. Within a world of increasing complexity, scarcity and dynamic change, the development of simple and effective indicators to assist in decision-making is of high value. The URV is one such an indicator. Here we propose three changes in the conventional use of the URV metric that should facilitate dialogue within the water resource management space, while improving the 
nuances with respect to its use within various different contexts.

\section{REFERENCES}

Alferink, L A \& Farmer-Dougan, V 2010. Brain(not) based education: Dangers of misunderstanding and misapplication of neuroscience research. Exceptionality, 18(1): 42-52. doi: 10.1080/09362830903462573.

Angelstam, P, Andersson, K, Annerstedt, M et al 2013. Solving problems in social-ecological systems: Definition, practice and barriers of transdisciplinary research. Ambio: A Journal of the Human Environment, 42(2): 254-265. doi: 10.1007/s13280-012-0372-4.

Argote, L \& Miron-Spektor, E 2011. Organizational learning: From experience to knowledge. Organization Science, 22(5): 1123-1137. doi: 10.1287/orsc.1100.0621.

Ashton, P 2000. Integrated catchment management: Balancing resource utilization and conservation. Occasional Paper No. 5, African Water Issues Research Unit (AWIRU), University of Pretoria.

Binns, J A, Illgner, P M \& Nel, E L 2001. Water shortage, deforestation and development: South Africa's Working for Water programme. Land Degradation and Development, 12(4): 341-355. doi: 10.1002/ldr.455.

Blersch, C L \& Du Plessis, J A 2017. Planning for desalination in the context of the Western Cape water supply system. Journal of the South African Institution of Civil Engineering, 59(1): 11-21. doi: 10.17159/2309-8775/2017/v59n1a2.

Blignaut, J N, Mander, M, Schulze, R, et al 2010. Restoring and managing natural capital towards fostering economic development: Evidence from the Drakensberg, South Africa. Ecological Economics, 69(6): 1313-1323.

Brisson, P \& Brisson, M 2010. Variable application and misapplication of cricoid pressure. Journal of Trauma E Acute Care, 69(5): 1182-1184. doi: 10.1097/TA.0b013e3181d2793e.

Costanza, R, Farber, S C \& Maxwell, J 1989. Valuation and management of wetland ecosystems. Ecological Economics, 1(4): 335-361. doi: 10.1016/0921-8009(89)90014-1.

De Lange, W 2006. Multi-criteria decision-making for water resource management in the Berg Water Management Area. PhD Thesis. Stellenbosch University.

Denby, K, Movik, S, Mehta, L \& Van Koppen, B 2016. The ‘Trickle Down' of IWRM: A case study of locallevel realities in the Inkomati Water Management Area, South Africa. Water Alternatives, 9(3): 473-492. DWA (Department of Water Affairs) 2011. Development of a reconciliation strategy for the Olifants River Water Supply System. Report No. WP10197. Pretoria: DWA. DWS (Department of Water and Sanitation) 2014. Feasibility study for the Mzimvubu Water Project: Cost estimates and economic analysis. Report No. P WMA 12/T30/00/5212/15. Pretoria: DWS.
Drury, C \& Tayles, M 1997. The misapplication of capital investment appraisal techniques. Management Decision, 35(2): 86-93. doi: 10.1108/00251749710160223.

Glantz, S A 1980. Biostatistics: How to detect, correct and prevent errors in the medical literature. Circulation, 61(1): 1-7. doi: 10.1161/01.CIR.61.1.1.

Goddard, R, Colloff, M J, Wise, R M, Ware, D \& Dunlop, M 2016. Values, rules and knowledge: Adaptation as change in the decision context. Environmental Science Policy, 57: 60-69. doi: 10.1016/j.envsci.2015.12.004.

Hoffman, J J \& Du Plessis, J A 2008. Water demand management: An economic viable option. Stellenbosch University. Available at: http://hdl.handle. net/10019.1/43899.

Hosking, S \& Du Preez, M 2002. Valuing water gains in the Eastern Cape's Working for Water Programme. Water SA, 28(1): 23-28. doi: 10.4314/wsa.v28i1.4863.

Joubert, A, Stewart, T J \& Eberhard, R 2003. Evaluation of water supply augmentation and water demand management options for the City of Cape Town. Journal of Multi-Criteria Decision Analysis, 12(1): 17-25. doi: 10.1002/mcda.342.

Larson, E J, Marais, C \& Görgens, A H M 2001. Water resources planning with recognition of alien vegetation eradication. Proceedings, 10th South African Hydrological Symposium, Pietermaritzburg, pp 26-28. Lowenberg, A D 1997. Why South Africa's apartheid economy failed. Contemporary Economic Policy, 15(3): 62-72. doi: 10.1111/j.1465-7287.1997.tb00478.x.

Mander, M, Jewitt, G, Dini, J et al 2017. Modelling potential hydrological returns from investing in ecological infrastructure: Case studies from the Baviaanskloof-Tsitsikamma and Umgeni catchments, South Africa. Ecosystems Services, 27: 261-271. doi: 10.1016/j. ecoser.2017.03.003.

Marais, C \& Wannenburgh, A M 2008. Restoration of water resources (natural capital) through the clearing of invasive alien plants from riparian areas in South Africa: Costs and water benefits. South African Journal of Botany, 74(3): 526-537. doi: 10.1016/j.sajb.2008.01.175.

Mckenzie, R S \& Wegelin, W 2009. Challenges facing the implementation of water demand management initiatives in Gauteng Province. Water SA, 35(2): 168-174. doi: 10.4314/wsa.v35i2.76735.

Morokong, T, Blignaut, J N \& Bester, R 2017. Determining the efficiency of contractors in clearing invasive alien plant species: The case of Mopani District, Limpopo Province, South Africa. African Journal of Agricultural Research Economics, 12(4): 276-288.

Movik, S, Mehta, L, Van Koppen, B \& Denby, K 2016. Emergence, interpretations and translations of IWRM in South Africa. Water Alternatives, 9(3): 456-472.

Nkambule, N P, Blignaut, J N, Vundla, T, Morokong, T \& Mudavanhu, S 2017. The benefits and costs of clearing invasive alien plants in northern Zululand, South Africa. Ecosystems Services, 27: 203-223. doi: 10.1016/j.ecoser.2017.04.011.
Preston, I R 2015. Water supply development decisionmaking in South Africa. MComm Dissertation. Grahamstown: Rhodes University.

Ruiters, C \& Matji, M P 2015. Water institutions and governance models for the funding, financing and management of water infrastructure in South Africa. Water SA, 41(5): 660-676. doi: 10.4314/wsa.v41i5.09.

Schreiner, B 2013. Viewpoint - Why has the South African National Water Act been so difficult to implement? Water Alternatives, 6(2): 239-245.

Siebrits, R, Winter, K \& Jacobs, I 2014. Water research paradigm shifts in South Africa. South African Journal of Science, 110(5-6): 1-9. doi: 10.1590/sajs.2014/20130296.

Siedlok, F \& Hibbert, P 2014. The organization of interdisciplinary research: Modes, drivers and barriers. International Journal of Management Reviews, 16(2): 194-210. doi: 10.1111/ijmr.12016.

Tapela, B N 2012. Social water scarcity and water use: Report to the Water Research Commission. Pretoria: Water Research Commission.

Tempelhoff, J 2017. The Water Act, No. 54 of 1956 and the first phase of apartheid in South Africa (1948-1960). Water History, 9(2): 189-213. doi: 10.1007/s12685-016-0181-y.

Turton, A \& Meissner, R 2002. The hydrosocial contract and its manifestation in society: A South African case study. In Turton, A \& Henwood, R (Eds). Hydropolitics in the Developing World: A Southern African Perspective. Pretoria: African Water Issues Research Unit (AWIRU), University of Pretoria, pp 37-60.

Van Niekerk, P \& Du Plessis, J 2013a. Hydrologiceconomic appraisal of life-cycle costs of inter-basin water transfer projects. Water SA, 39(4): 539-548. doi: 10.4314/wsa.v39i4.13.

Van Niekerk, P \& Du Plessis, J 2013b. Unit Reference Value: Application in appraising inter-basin water transfer projects. Water SA, 39(4): 549-54. doi: 10.4314/wsa.v39i4.14.

Van Wilgen, B W \& Wannenburgh, A 2016. Co-facilitating invasive species control, water conservation and poverty relief: Achievements and challenges in South Africa's Working for Water programme. Current Opinion in Environmental Sustainability, 19: 7-17.

Van Wilgen, B W, Little, P, Chapman, R, Görgens, A, Willems, T \& Marais, C 1997. The sustainable development of water resources: History, financial costs, and benefits of alien plant control programmes. South African Journal of Science, 93(9): 404-411.

Vundla, T, Blignaut, J N, Nkambule, N, Morokong, T \& Mudavanhu S 2016. The opportunity cost of not utilising the woody invasive alien plant species in the Kouga, Krom and Baviaans catchments in South Africa. South African Journal of Economic and Management Sciences, 19(5): 814-830. doi: 10.17159/2222-343/2016/v19n5a8. 